\title{
Laboreal
}

Volume $17 \mathrm{~N}^{\circ} 2$ | 2021

Trabalho e Território

\section{"Psicologia Social do Trabalho": uma intervenção sobre o mundo do trabalho na América Latina}

"Psicologia Social do Trabalho": una intervención para el mundo laboral en América Latina

"Psicologia Social do Trabalho": une intervention pour le monde du travail en Amérique latine

"Psicologia Social do Trabalho": an intervention for the world of work in Latin America

\section{Hernán Camilo Pulido Martínez}

\section{(2) OpenEdition}

\section{Journals}

Edição electrónica

URL: https://journals.openedition.org/laboreal/18229

DOI: $10.4000 /$ laboreal. 18229

ISSN: 1646-5237

\section{Editora}

Universidade do Porto

\section{Refêrencia eletrónica}

Hernán Camilo Pulido Martínez, «"Psicologia Social do Trabalho": uma intervenção sobre o mundo do trabalho na América Latina», Laboreal [Online], Volume 17 N² 2 2021, posto online no dia 01 dezembro 2021, consultado o 05 dezembro 2021. URL: http://journals.openedition.org/laboreal/18229 ; DOl: https://doi.org/10.4000/laboreal.18229

Este documento foi criado de forma automática no dia 5 dezembro 2021.



Laboreal está licenciado com uma Licença Creative Commons - Atribuição-NãoComercial 4.0 Internacional. 


\section{"Psicologia Social do Trabalho": uma intervenção sobre o mundo do trabalho na América Latina}

"Psicologia Social do Trabalho": una intervención para el mundo laboral en América Latina

"Psicologia Social do Trabalho": une intervention pour le monde du travail en Amérique latine

"Psicologia Social do Trabalho": an intervention for the world of work in Latin America

Hernán Camilo Pulido Martínez

\section{NOTA DO EDITOR}

\section{Traduzido por :}

Marcia Hespanhol Bernardo (marciahespanhol@hotmail.com)

Leny Sato (lenysato@usp.br)

Aceite: junho/2021

1 Ao contrário dos textos de psicologia organizacional que inundam as livrarias, a proposta apresentada no livro Psicologia Social do Trabalho é revigorante, interessante e muito desafiadora para aqueles psicólogos que buscam compreender o mundo do trabalho na América Latina para além das fórmulas preconcebidas. Sem dúvida, essa obra pode ser considerada uma intervenção, tanto no âmbito da disciplina psicológica, como nos locais de trabalho. Muitos são os motivos pelos quais esse texto que nos é apresentado por acadêmicos brasileiros pode ser tomado como uma intervenção. Em uma definição ampla, pode-se dizer que intervenção basicamente significa "estar entre" (Schvarstein, 1992). A partir dessa definição, a questão, então, que deve ser 
colocada sobre a mesa refere-se a "entre" quais instâncias, "entre" quais temas e "entre" quais pessoas o livro se coloca.

\section{Introduz a categoria trabalho}

2 A estrutura do livro adotada pelos autores assinala sua preocupação em tomar como ponto de partida para sua reflexão os problemas laborais típicos do Brasil. A título de exemplo, os investigadores se propõem a examinar pontos centrais da história do trabalho, os quais imprimem características particulares ao mundo do trabalho naquele país. Essas reflexões não são usadas apenas como um contexto no qual fenômenos psicológicos ocorrem. Elas também servem para localizar a problemática e os argumentos que serão desenvolvidos. Como evidências das possibilidades que a introdução da categoria trabalho abre para configurar uma psicologia social, os distintos capítulos se apropriam dessa categoria de diversas maneiras para mostrar como as especificidades locais levam à consolidação de propostas alternativas e pertinentes aos problemas que afligem os trabalhadores.

3 A introdução da categoria trabalho resulta em um "estar entre" a reflexão sobre os problemas do trabalho e a banalização que se faz na psicologia hegemônica, representada pelas versões industrial-organizacional, que separam o trabalho como tal de suas análises. Nas versões hegemônicas da psicologia, paradoxalmente, o trabalho constitui apenas um pano de fundo sobre o qual os fenômenos psicológicos ocorrem. Por outro lado, na psicologia social que nos é ensinada, o trabalho é parte constitutiva do ser humano e um dos âmbitos centrais no qual se dá a socialização. Nesse sentido, ao introduzir a categoria trabalho como eixo articulador dos argumentos que se apresentam nos diferentes capítulos, abre-se uma série de perspectivas acerca de como os seres humanos se constituem no âmbito do trabalho, de acordo com a história precedente e as formas que, ao longo do tempo, consolidaram um tipo particular de organização do trabalho.

Isso não significa que o livro se transforme em uma amostra exótica da produção de conhecimento pertinente apenas para o Brasil. Ao contrário, o fato de apresentar um modo de considerar como os fenômenos psicológicos se dão devido às formas que o trabalho assume fornece as ferramentas para que, em outros países, com situações e características semelhantes, esse livro seja utilizado como uma ferramenta básica para pensar o mundo do trabalho local a partir de perspectivas inter e transdisciplinares.

\section{Delimita um campo}

O livro também faz uma intervenção no sentido de demarcar uma área do conhecimento em relação aos estudos que se interessam pelo mundo laboral. A introdução do trabalho como fonte de análise traz consigo uma articulação de conceitos que vêm responder aos fortes questionamentos gerados pela inclusão desta categoria. $O$ texto da Psicologia Social do Trabalho representa, assim, uma intervenção, posicionando-se como um campo alternativo, caracterizado, entre outras coisas, por considerar as mais diversas formas que o trabalho assume no Brasil e, por que não, na América Latina. 
6 O livro é uma ferramenta para psicólogos em formação e para profissionais, não apenas dessa disciplina, que estejam interessados em lidar com os problemas do trabalho de forma complexa. A delimitação do campo que se formula possibilita que os autores reflitam sobre as possibilidades e exigências que ele possui. Se a psicologia organizacional industrial convencional está localizada no nível das relações entre a gerência e os trabalhadores, a psicologia social do trabalho estabelece relações diretamente com os trabalhadores. Para estabelecer essa relação - e aqui está uma exigência crucial dessa psicologia -, é necessário considerar como eixo do campo as questões colocadas pelos próprios trabalhadores, pelas organizações que os agrupam, como os sindicatos, entidades oficiais que promovem as políticas públicas e/ou ONGs interessadas em democratizar as relações que se estabelecem na sociedade.

7 Pois bem, em termos de demarcação, essa obra oferece uma contribuição ao mostrar tanto as condições de possibilidade que permitiram o surgimento de uma psicologia social do trabalho, como o próprio cotidiano do trabalho que colaborou para constituíla. Assim, os autores apontam os momentos pelos quais o Brasil passou em sua história em termos dos efeitos que se produziram no mundo do trabalho, os antecedentes conceituais e metodológicos que se deram nas ciências sociais e na própria psicologia, as mais variadas formas como o trabalho se manifestou na vida cotidiana, assim como os movimentos sociais que prepararam o terreno para o estabelecimento de alianças com diferentes atores, não apenas do âmbito acadêmico, de modo que pudesse estabelecer distintas maneiras de conceber e levar a cabo a produção de conhecimento.

\section{Reconhece um grupo acadêmico}

8 Por meio dessa obra, os autores mostram-se como um grupo de pesquisadores com interesses comuns, posições éticas e políticas compartilhadas e temas de pesquisa bastante diversificados. Ao longo do livro, são descritas as experiências e vicissitudes que o trabalho alternativo e crítico pode enfrentar, bem como as conjunturas que possibilitaram que se configurassem como um grupo de investigadores. Nesse sentido, o livro torna-se uma espécie de farol que pode permitir que outros grupos de investigadores, localizados em outros espaços geográficos, pensem sobre as condições particulares que são necessárias para que o empreendimento crítico tenha possibilidades de desenvolvimento. 0 fato de a história ter um lugar importante para pensar os problemas do trabalho faz com que os autores reflitam sobre sua própria experiência como produtores de conhecimento e, portanto, que a retrate como exemplo do caminho que percorreram para formular a proposta do campo.

\section{Considera outras formas de trabalho}

9 O complexo mundo do trabalho na América Latina com seu amplo leque de manifestações, que abrange, para citar apenas algumas, o trabalho informal, os pequenos negócios, a sobrevivência comunitária, as fábricas recuperadas, as cooperativas de trabalho, entre outros, nunca foram foco de interesse da psicologia concentrada, fundamentalmente, no formato 'emprego'. Por outro lado, a psicologia social do trabalho dá visibilidade a essas formas invisíveis. Aliás, são elas que despertam 
o maior interesse dos autores. Essa é uma operação de muita relevância, pois grande parte da força de trabalho na América Latina se encontra nesses tipos de trabalho.

Claro, não se trata de uma cruzada contra o emprego ou uma reivindicação romântica dessas formas de trabalho postas de lado. Trata-se, sim, de examinar as complexidades que se estabelecem no mercado de trabalho e os modos pelos quais as diferentes formas de trabalhar se complementam para sustentar a economia, precarizar o trabalho e estabelecer relações entre o rural e o urbano, entre o formal e o informal, entre o trabalho regulado e o não regulado. Nessas condições, ao apresentar modos de trabalho desconhecidos, invisibilizados ou não suficientemente explorados por outras perspectivas, como a psicologia industrial-organizacional, a psicologia social do trabalho muda o olhar sobre a relação entre emprego e outros meios de trabalho, nos permitindo pensar não só nas condições do primeiro, mas nas condições de todas as outras múltiplas formas que, paralelamente, têm lugar no variado espectro de modalidades de trabalho presentes na contemporaneidade.

\section{Promove um método}

11 A psicologia social do trabalho proposta no livro faz uma aposta na qual teoria e prática, pesquisa e intervenção não são considerados momentos independentes ou separados no processo de conhecimento. A teoria ilumina a prática e a prática ilumina a teoria. Visando romper esta separação, são examinados os problemas concretos que os trabalhadores têm no seu dia a dia. Com ponto de vista privilegiado dos trabalhadores, contribui para construir explicações sobre os fenômenos do trabalho e sobre a constituição dos próprios trabalhadores que não têm como característica central um cunho individualista, que responsabiliza e culpabiliza os que trabalham.

Em outras palavras, os resultados dos exercícios de pesquisa-intervenção se distanciam das visões hegemônicas que privilegiam a pesquisa para alcançar eficiência e produtividade, como ocorre na psicologia organizacional-industrial. Em vez disso, com uma visão holística, a psicologia social do trabalho investiga e intervém não para os trabalhadores, mas com eles. Com esse posicionamento na construção do conhecimento que se apresenta nesta contra-psicologia, procura-se naturalmente construir relações mais equitativas entre investigadores e investigados, na qual os primeiros não observam os segundos e nem prescrevem receitas com os conhecimentos deles obtidos. A construção do conhecimento é realizada como uma relação negociada e colaborativa entre acadêmicos e trabalhadores, bem como outros atores que podem participar, regular ou intervir no mundo do trabalho. Embora a democratização das relações entre os participantes de uma investigação não seja nova para as ciências sociais, nem para outros ramos da psicologia, é relativamente nova para os ramos colonizados que tratam do trabalho por meio de visões positivistas e superficiais do conhecimento.

Além disso, em termos de método, é importante destacar que os autores consideram que todas as situações de trabalho são complexas. A que se referem quando afirmam que as situações de trabalho são complexas? Em primeiro lugar, que os ângulos de um problema de trabalho não se revelam em todas as suas dimensões com observações indiretas e pontuais, como costuma acontecer em versões nas quais, por exemplo, a medição do clima organizacional ou da cultura de trabalho são fundamentais. Em vez disso, a exploração da experiência dos trabalhadores fornece uma perspectiva ampla de quais são e quais têm sido os problemas do trabalho em âmbitos específicos. Essa 
perspectiva significa que os autores do livro escolheram a experiência particular do trabalho como foco, o qual pode ser estudado a partir de metodologias participativas de natureza qualitativa e de longa permanência no campo. A etnografia, a história oral, o resgate de trajetórias de trabalho, só para citar alguns modos de proceder, são coerentes com esse tipo de proposta de pesquisa-intervenção, na qual se definem os problemas cotidianos dos trabalhadores para enfrentar suas causas, com o objetivo de que os resultados sejam úteis para os próprios trabalhadores.

Resta notar que os autores apontam que, adicionalmente, quando pesquisa e intervenção não se separam - e aqui reside outra característica que situa a psicologia social do trabalho no campo das contra-psicologias - se apaga ou se borra mais um dos limites que a psicologia tradicional estabeleceu para si, ou seja, rompe-se a divisão entre a psicologia pura ou teórica e psicologia aplicada.

\section{Requer a inter e a transdisciplinaridade}

Da mesma forma, o livro pode ser considerado uma intervenção em relação ao modo como propõe suas articulações com outras áreas afins para a compreensão dos problemas do trabalho. A proposta de uma psicologia social, que se responsabilize pela situação de trabalho, surge em meio às indagações sobre a interdisciplinaridade que, contemporaneamente, ronda os cursos de psicologia. Na psicologia social do trabalho que os autores configuram, a interdisciplinaridade não é um desejo a ser alcançado, é um fato necessário para poder resolver as questões que lhe são formuladas. A experiência particular de cada investigador e do grupo ao qual pertence, bem como as vivências dos trabalhadores com os quais se partilha a indagação, fazem com que os problemas do trabalho se definam num contexto amplo, num panorama extenso, no qual se encontra o jogo entre a particularidade de um caso que ocorre no mundo do trabalho e o contexto histórico, político, social, econômico e cultural no qual ocorre.

Como recomendado para quem tem interesse em realizar trabalhos semelhantes aos apresentados, uma equipe formada por profissionais de diferentes áreas do conhecimento é o ideal. A esse respeito, é importante notar que, nas próprias raízes da psicologia social do trabalho, havia campos provenientes de múltiplas vertentes, que, ao mesclar-se, acabavam sendo mais do que um acréscimo de perspectivas de disciplinas independentes. A medicina social lationamericana e o movimento operário italiano foram convocados no momento de lançar as bases conceituais para a intervenção nos problemas do trabalho que esta contra-psicologia pretende enfrentar.

17 As categorias eleitas por esta contra-psicologia destacam a necessidade de considerar as perspectivas inter e transdisciplinares. As práticas cotidianas, os sentidos construídos, o conflito entre capital e trabalho, bem como a construção da identidade, considerados como foco de estudos, requerem relações entre campos do saber instituídos, assim como a criação de olhares transdisciplinares. Cada um desses campos e a relação entre os temas apontados coloca a necessidade de uma série de diálogos entre perspectivas que permitam dar conta deles. Essa tarefa não é fácil, visto que se trata de combinar de forma inter ou transdisciplinar as ciências sociais, a filosofia, a ergonomia, a medicina e a psicologia num intenso diálogo sobre as situações concretas do cotidiano de trabalho, que são consideradas como o ponto onde se encontram os contextos macrossociais com a formação da subjetividade por meio da experiência vivida no trabalho. 
18 Aqui, entretanto, como apontam os autores, há uma certa fragilidade do conhecimento que se apresenta, pois ainda falta mais elaboração e, possivelmente, articulação entre os campos que podem ser utilizados para levar à transformação do trabalho. Por exemplo, uma psicologia ainda mais histórica poderia demorar a ser formulada e, com ela, poder-se-ia, como indicado, fazer inferências sobre a relação entre a constituição do sujeito e as mudanças no capitalismo nas condições particulares e múltiplas que possui o mundo de trabalho.

\section{Uma posição política comprometida}

19 Nesse ponto, a intervenção que se apresenta no livro, por um lado, relaciona-se a "estar entre" aquelas perspectivas da psicologia convencional que assumem que se pode fazer uma série de melhorias constantes que não questionam a ordem do trabalho que gera problemas de iniquidade, exclusão, precarização e desemprego e, por outro lado, entre aquelas que assumem perspectivas qualitativas que produzem conhecimento a partir dos trabalhadores para conhecê-los em maior profundidade e, então, realizar ações que melhorem o desempenho administrativo. Irrompe, então, a psicologia social do trabalho para formular uma perspectiva que pressupõe que o conhecimento deve ser produzido não a partir de e para o outro, mas, nesse caso, com os trabalhadores.

Dessa forma, é impossível pensar a neutralidade, uma vez que a reflexão parte da consideração de que os locais de trabalho são antes de tudo espaços políticos. Por isso, como afirmam os autores, é fundamental partir da vivência no cotidiano de trabalho para examinar as contradições do sistema que ficam patentes nos fazeres no dia-a-dia de trabalho. Nesse sentido, o conhecimento é produzido não para instruir o trabalhador. Isso porque é ele que é um especialista nas contradições que enfrenta, bem como é quem melhor se investiga e intervém - para o desagrado de outros ramos da psicologia - para a promoção de ações afirmativas, nas quais trabalhadores e investigadores são atores políticos capazes de influenciar e modificar os ambientes de trabalho.

O processo de investigação e intervenção abre um espaço para o trabalhador interagir com o que será o seu resultado. Portanto, deve-se destacar que, talvez, aí resida a sua possível eficácia, uma vez que a transformação das condições de trabalho estará diretamente vinculada àqueles a quem ela afeta. Deve-se acrescentar que esse posicionamento na condução da pesquisa-intervenção também deveria exigir uma reflexão do investigador como um trabalhador que, de certa forma, na mesma condição do investigado, compreende seu cotidiano em contato com outras cotidianidades de trabalho diferentes em algum grau. Na sua qualidade de investigador/trabalhador, talvez uma das principais contribuições esteja representada na sua competência para definir condições físicas de trabalho nas quais a organização do trabalho se processa, na sua capacidade de fazer análises críticas das relações sindicais patronais, nas suas possibilidades de recontar a história do trabalho no contexto em estudo, bem como recoletar informações sobre as condições e relações de trabalho.

Além disso, as atividades de produção de conhecimento realizadas são uma atividade política ao menos nos seguintes aspectos. Na medida em que se descreve e se analisa as condições de trabalho, os diferentes atores acadêmicos, sindicais e governamentais podem torná-las públicas, assim, colocando na agenda social condições, por exemplo, precárias, prejudiciais, desiguais, para sua possível transformação por meio de 
diferentes estratégias. Da mesma forma, os resultados das investigações construídas com os trabalhadores devem ser passíveis de serem utilizados como "munição" para mudar o trabalho. Adicionalmente, o investigador tem um papel político explícito como "ativista" na medida em que seu papel e suas práticas estão reconhecidamente comprometidos com os trabalhadores. Deve, portanto, objetivar levar a cabo ações afirmativas conjuntas que recoloquem as tensões presentes entre capital, trabalho e Estado, a fim de construir uma reflexão sobre as próprias possibilidades de transformação social necessária para a construção de novas relações de poder no trabalho.

Resta considerar que, em muitas perspectivas críticas propostas em relação à psicologia e ao trabalho, se assume um papel diagnóstico que deixa um sabor de pessimismo e imobilidade. A perspectiva crítica foi muito valiosa para desvendar as implicações que a psicologia tem quando aplicada ao mundo do trabalho. Porém, ao contrário do que acontece em algumas áreas da disciplina, a crítica não tem conseguido questionar fortemente nem o conhecimento, nem as práticas que ocorrem nos âmbitos de trabalho. A prova disso é que não se conseguiu nenhum tipo de desgaste da psicologia hegemônica presente nos âmbitos laborais. A psicologia social do trabalho que está contida nesta obra é uma intervenção, que em si já significa uma mobilização que não volta, ou melhor, não se detém na questão pontual de propor uma psicologia melhorada. O livro faz parte de um programa no qual intervenção e investigação não se separam, mas são constitutivas uma da outra. Portanto, este texto não pode ser separado do programa que os acadêmicos que fazem parte dessa obra desenvolvem há décadas.

Para finalizar, cabe apenas assinalar uma indagação adicional: se um tipo de conhecimento diferente, complexo, político e transformador está se desdobrando ao longo do livro, será que se deve querer mantê-lo dentro dos limites da disciplina psicológica? Talvez seja o momento de romper de uma vez por todas com as restrições que se impõem para permanecer dentro do complexo psi.

\section{BIBLIOGRAFIA}

Parker, I. (2007). Revolution in Psychology: Alienation to Emancipation. Londres: Pluto Press.

Schvarstein, L. (1992). Psicologia Social de las Organizaciones. Nuevos Enfoques. Buenos Aires: Paidos.

\section{AUTOR}

\section{HERNÁN CAMILO PULIDO MARTÍNEZ}

https://orcid.org/0000-0003-1071-2784

Pontificia Universidad Javeriana, Bogotá, Carrera 7 No. 40-00. Edificio Manuel Briceño, of 203. 
Bogotá, Colombia

cpulido@javeriana.edu.co 